\title{
Tongue-tie Management: A Case Report
}

\author{
Amrita Kumari ${ }^{1}$, Malvika B Bansal ${ }^{2}$, Karan H Asrani ${ }^{3}$, Akanksha Gaud $^{4}$, Ashish Yadav ${ }^{5}$, Swati Sharma ${ }^{6}$, Meenakshi Meena ${ }^{7}$
}

\author{
Abstract \\ treated by using a diode laser. \\ Keywords: Ankyloglossia, Frenectomy, Laser, Recession. \\ Journal of Mahatma Gandhi University of Medical Sciences \& Technology (2019): 10.5005/jp-journals-10057-0096
}

Tongue-tie or ankyloglossia is a rare congenital anomaly. It is a short, thick, and fibrosed lingual frenulum which causes restriction in function of the tongue and also in speech. Tongue is an accessory organ, and it helps in deglutition, mastication, and speech. Tongue-tie also causes lingual recession of the teeth. So, it is necessary to treat at the right time. In this case, the patient has a lingual tongue-tie which has been

\section{INTRODUCTION}

Tongue is a muscular organ in the mouth, which helps in swallowing, speech, tasting, and feeding. Tongue is multifunctional and when it gets tie (ankyloglossia), it limits some of its activity. In 1960, Wallace defined tongue-tie as a condition in which the tip of the tongue cannot be protruded beyond lower incisor teeth because of a short frenulum linguae. ${ }^{1}$ Kotlow gave the classification for ankyloglossia (Table 1). ${ }^{2}$

A normal motion range of tongue is indicated when the tip of tongue is able to protrude outside the mouth without clefting, when lingual frenum allows a normal swallowing, when there is no speech difficulties due to limitation of the tongue movement, and when it can sweep the upper and lower lips easily, without straining. ${ }^{1}$ Any condition restricting free movement of the tip of the tongue and preventing it from touching the anterior palate, then it may interfere with the development of an adult swallow and may result in an open bite deformity. ${ }^{3}$

\section{Case Description}

A 26-year-old male patient reported to the Department of Periodontology in Mahatma Gandhi Dental College and Hospital, Jaipur, with his chief complain of bad breath and bleeding gums and also had difficulty in tongue movement and speaking. Because of limited tongue movement, the patient complained of difficulty in maintaining oral hygiene. Clinically intraoral examination revealed short lingual frenum and restricted tongue movements (Fig. 1). The patient was diagnosed with class III ankyloglossia according to Kotlow's classification (Table 1).

\section{TREATMENT}

The patient was advised for blood investigation. After completing phase I therapy, surgical lingual frenectomy was undertaken under local anesthesia with $2 \%$ lignocaine and 1:80,000 adrenaline. The

Table 1: Kotlow's classification

\begin{tabular}{ll}
\hline Class I: Mild ankyloglossia & $12-16 \mathrm{~mm}$ \\
Class II: Moderate ankyloglossia & $8-11 \mathrm{~mm}$ \\
Class III: Severe ankyloglossia & $3-7 \mathrm{~mm}$ \\
Class IV: Complete ankyloglossia & $<3 \mathrm{~mm}$ \\
\hline
\end{tabular}

${ }^{1-7}$ Department of Periodontology, Mahatma Gandhi Dental College and Hospital, Mahatma Gandhi University of Medical Sciences and Technology, Jaipur, Rajasthan, India

Corresponding Author:Amrita Kumari, Department of Periodontology, Mahatma Gandhi Dental College and Hospital, Mahatma Gandhi University of Medical Sciences and Technology, Jaipur, Rajasthan, India, Phone: +91 8294102340, e-mail: amritasweet1414@gmail.com

How to cite this article: Kumari A, Bansal MB, Asrani KH, et al. Tonguetie Management: A Case Report. J Mahatma Gandhi Univ Med Sci Tech 2019;4(1):32-34.

Source of support: Nil

Conflict of interest: None

tongue was stabilized with silk sutures, and it was placed at the tip of the tongue. A lingual frenectomy were performed by using soft tissue diode laser (Fig. 2). Saline irrigation was given, and suture was placed (Fig. 3). Suture removal was done after 1 week, and the postoperative image showed partial healing (Fig. 4). The patient was referred to speech therapist for correction of speech defects. After 1 month, the patient showed healing with no scar formation (Fig. 5).

\section{Discussion}

Tongue-tie or ankyloglossia is a diagnostic challenge for dentists. It is a congenital condition with a prevalence of about $5 \% .{ }^{4}$ Boys are affected more than girls with a ratio of $2: 1 .^{5}$ It is important to properly diagnose before going for the surgical intervention. There is a positive relationship between tongue-tie and speech disorder. ${ }^{6}$ For proper diagnosis of the tongue-tie, there should be a routine dental examination for children under the age of 3 years. ${ }^{2}$ Recommending treatment for short lingual attachment, dentist often delay unless there is speech or tongue movement difficulties. ${ }^{2}$ Surgical intervention like frenotomy, frenectomy, or frenuloplasty is seen beneficial for tongue-tie. Patients should be educated about tongue-tie and its long-term effect, so that they can go for the possible therapy. ${ }^{2,6}$ Ankyloglossia varies from 0.1 to $10.7 \% .^{7}$ As we know that tongue is an accessory organ that helps us in deglutition, mastication, and speech. Tonguetie patients get trouble in speaking with the words that sound from the tongue tip like $s, n, t, d, j, z h, c h, t h, d g$, and $I .{ }^{8}$ It also causes more thrust of the tongue against anterior mandible

() The Author(s). 2019 Open Access This article is distributed under the terms of the Creative Commons Attribution 4.0 International License (https://creativecommons. org/licenses/by-nc/4.0/), which permits unrestricted use, distribution, and non-commercial reproduction in any medium, provided you give appropriate credit to the original author(s) and the source, provide a link to the Creative Commons license, and indicate if changes were made. The Creative Commons Public Domain Dedication waiver (http://creativecommons.org/publicdomain/zero/1.0/) applies to the data made available in this article, unless otherwise stated. 

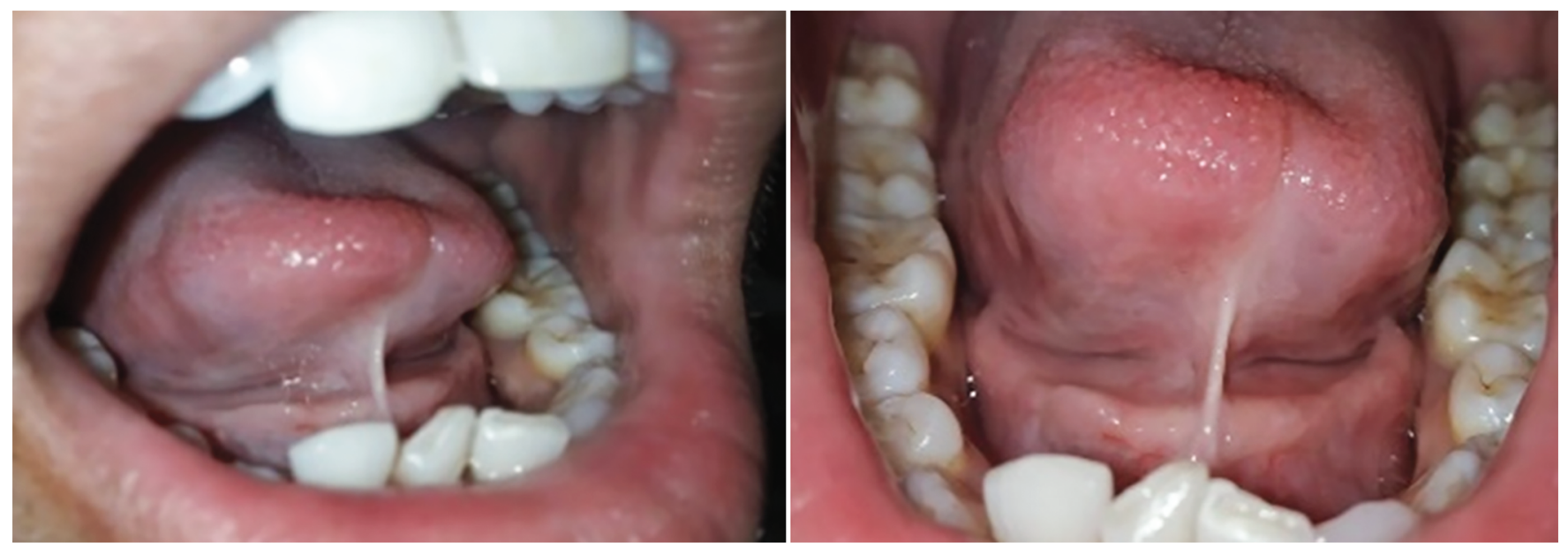

Figs $1 \mathrm{~A}$ and B: Preoperative view showing ankyloglossia

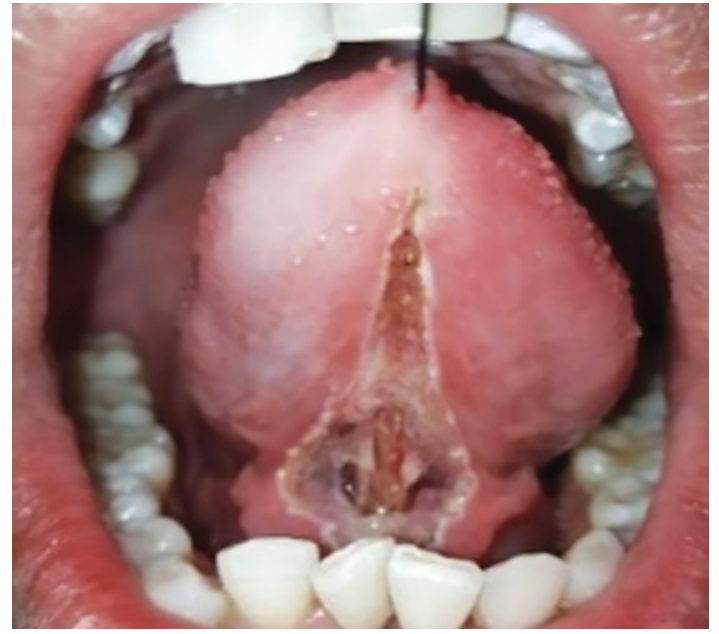

Fig. 2: Frenectomy incision done by using diode laser

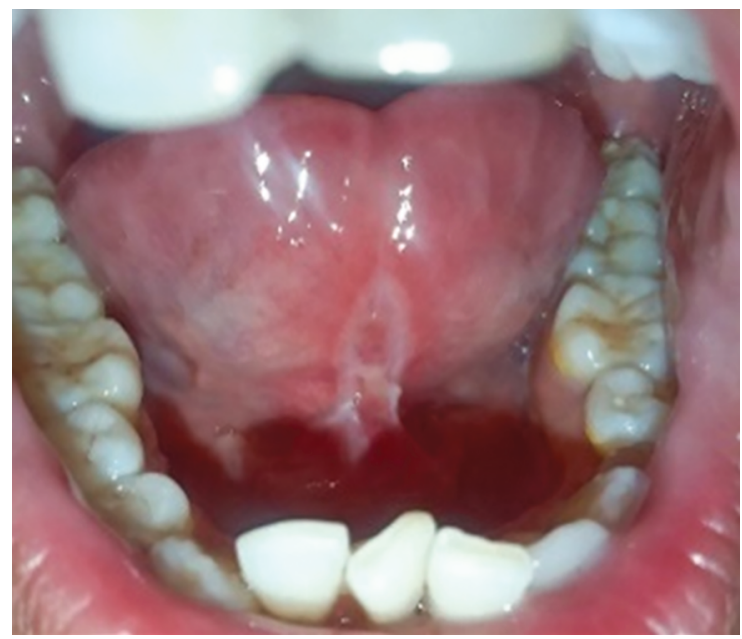

Fig. 4: Postoperative view after 10 days

and produces a mandibular prognathism due to lack of free movement of the tongue. ${ }^{9}$ Gingival recession has also been seen on the lingual surfaces. ${ }^{9}$ In this case report, ankyloglossia was treated with surgical frenectomy procedure by using diode laser.

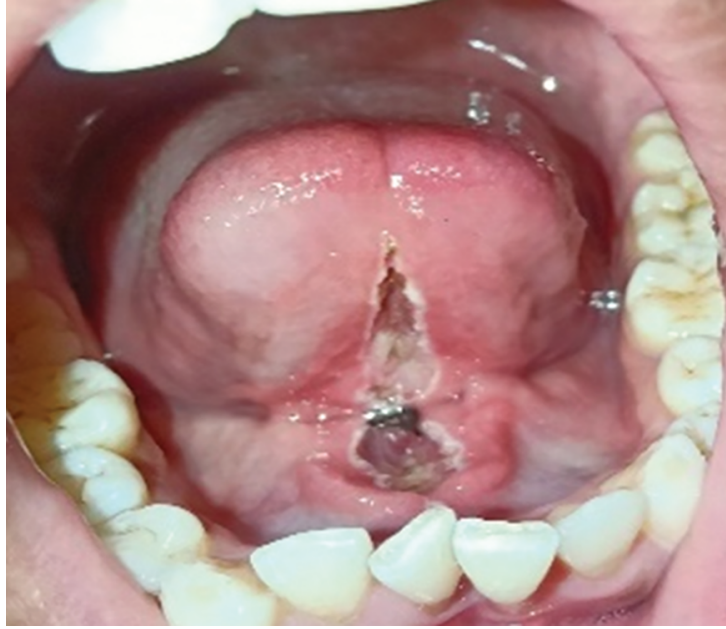

Fig. 3: Sutures placed

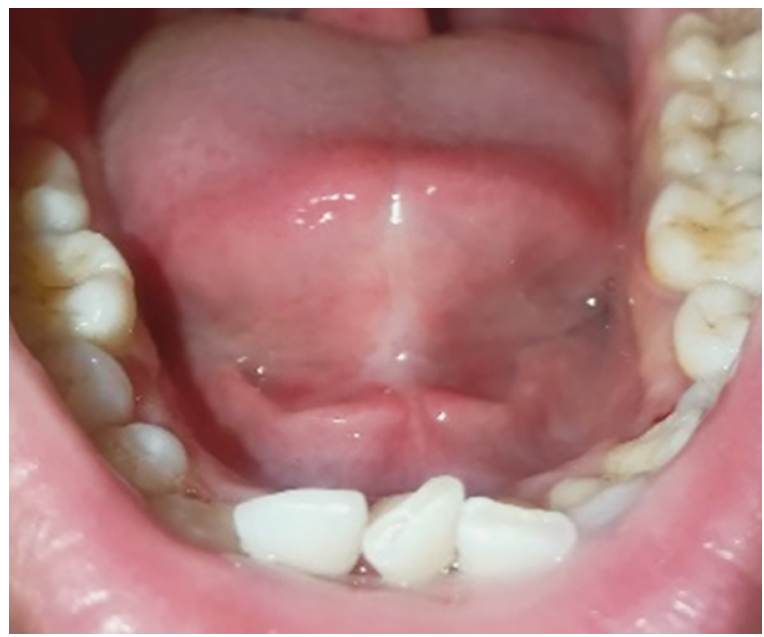

Fig. 5: Postoperative view after 1 month

The treatment can also be done with conventional scalpel, but visibility of working area can be hindered due to excess bleeding, and in that case, diode laser is an excellent tool that provides better visibility with minimal bleeding as it is bactericidal and 
anticoagulant. ${ }^{10}$ Laser provides less postoperative pain than that obtained by conventional therapy.

\section{CONCLUSION}

Tongue-tie becomes difficult for the patient due to limitation of tongue mobility and speech problem. So, it is necessary to treat it on correct time which can be improved by surgical interventions.

\section{References}

1. Wallace AF. Tongue tie. Lancet 1963;2(7304):377-378. DOI: 10.1016/ s0140-6736(63)93057-5.

2. Kotlow LA. Ankyloglossia (tongue-tie): a diagnostic and treatment quandary. Quintessence Intl 1999;30(4):259-262.

3. Whitman $\mathrm{CL}$, Rankow RM. Diagnosis and management of ankyloglossia. Amer J Orthod 47(6):423-428. DOI: 10.1016/00029416(61)90221-4 1961.
4. Ballard JL, Auer CE, Khoury JC. Ankyloglossia: assessment, incidence, and effect of frenuloplasty on the breastfeeding dyad. Pediatrics 2002;110(5):e63. DOI: 10.1542/peds.110.5.e63.

5. Segal LM, Stephenson R, Dawes M, et al. Prevalence, diagnosis, and treatment of ankyloglossia: methodologic review. Can Fam Physician 2007;53(6):1027-1033.

6. Ayer FJ, Hilton LM. Treatment of ankyloglossia: reported of a case. ASDC J Dent Child 1977;44(3):69-71.

7. Chaubal TV, Dixit MB. Ankyloglossia and its management. Indian Soc Periodontal 2011;15(3):270-272. DOI: 10.4103/0972-124X.85673.

8. Messner AH, Lalakea ML. The effect of ankyloglossia on speech in children. Otolaryngol Head Neck Surg 2002;127(6):539-545. DOI: 10.1067/mhn.2002.129731.

9. Reddy NR, Marudhappan Y, Devi R, et al. Clipping the (tongue) tie. J Indian Soc Periodontal 2014;18(3):395-398. DOI: 10.4103/0972124X.134590.

10. Patil HP, Bhoir SS. Treatment of ankyloglossia by diode laser. J Dent Lasers 2017;11(2):65-68. DOI: 10.4103/jdl.jdl_17_17. 